\title{
Understanding the aerosol information content in multi-spectral reflectance measurements using a synergetic retrieval algorithm
}

\author{
D. Martynenko ${ }^{1}$, T. Holzer-Popp ${ }^{1}$, H. Elbern ${ }^{2}$, and M. Schroedter-Homscheidt ${ }^{1}$ \\ ${ }^{1}$ German Aerospace Center (DLR) e.V., Deutsches Fernerkundungsdatenzentrum (DFD), Oberpfaffenhofen, Germany \\ ${ }^{2}$ Rhenish Institute for Environmental Research (RIU) at the University of Cologne, and Institute for Chemistry and Dynamics \\ of the Geosphere - 2, Research Centre Jülich, Germany
}

Received: 7 May 2010 - Published in Atmos. Meas. Tech. Discuss.: 8 June 2010

Revised: 11 November 2010 - Accepted: 12 November 2010 - Published: 19 November 2010

\begin{abstract}
An information content analysis for multiwavelength SYNergetic AErosol Retrieval algorithm SYNAER was performed to quantify the number of independent pieces of information that can be retrieved. In particular, the capability of SYNAER to discern various aerosol types is assessed. This information content depends on the aerosol optical depth, the surface albedo spectrum and the observation geometry. The theoretical analysis is performed for a large number of scenarios with various geometries and surface albedo spectra for ocean, soil and vegetation. When the surface albedo spectrum and its accuracy is known under cloud-free conditions, reflectance measurements used in SYNAER is able to provide for 2-4 ${ }^{\circ}$ of freedom that can be attributed to retrieval parameters: aerosol optical depth, aerosol type and surface albedo.

The focus of this work is placed on an information content analysis with emphasis to the aerosol type classification. This analysis is applied to synthetic reflectance measurements for 40 predefined aerosol mixtures of different basic components, given by sea salt, mineral dust, biomass burning and diesel aerosols, water soluble and water insoluble aerosols. The range of aerosol parameters considered through the 40 mixtures covers the natural variability of tropospheric aerosols. After the information content analysis performed in Holzer-Popp et al. (2008) there was a necessity to compare derived degrees of freedom with retrieved aerosol optical depth for different aerosol types, which is the main focus of this paper.
\end{abstract}

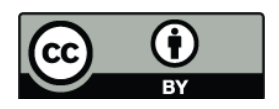

Correspondence to: D. Martynenko (dmytro.martynenko@dlr.de)
The principle component analysis was used to determine the correspondence between degrees of freedom for signal in the retrieval and derived aerosol types. The main results of the analysis indicate correspondence between the major groups of the aerosol types, which are: water soluble aerosol, soot, mineral dust and sea salt and degrees of freedom in the algorithm and show the ability of the SYNAER to discern between this aerosol types.

The results of the work will be further used for the development of the promising methodology of the construction error covariance matrices in the assimilation system.

\section{Introduction}

Several satellite instruments measuring backscattered solar radiation are currently used to monitor atmospheric aerosols. But there is a limited number of retrieval methods which are capable to retrieve and classify different aerosol types. The characterization of aerosols using satellite observations is challenging due to their variability in many respects, such as composition, size, particle shape and vertical distribution. In order to determine as many relevant aerosol parameters as possible, radiometric and polarimetric observations in a broad wavelength range with many viewing angles and a high spatial and spectral resolution would be optimal (Chowdhary et al., 2001). However, such measurements are technically challenging.

In recent years the satellite monitoring capabilities to derive maps of aerosol optical depth (AOD) have increased tremendously. A good overview of different satellite retrieval principles for deriving AOD is presented in Kaufman et al. (1997a) and a review of achieved AOD retrieval

Published by Copernicus Publications on behalf of the European Geosciences Union. 
capabilities is given in Kaufman et al. (2002). Examples of satellite retrieval of additional aerosol optical properties include the Angstrom coefficient, (e.g. AATSR dual view, Veefkind et al., 1999) and the separation into fine and coarse mode aerosols (e.g. MODIS multi-spectral collection 5, Levy et al. (2007); fine mode AOD only by POLDER polarized multi-spectral, Deuzé et al., 2001). Further examples of aerosol characterisation use a choice from pre-defined aerosol types (e.g. MISR multi-angle, Kahn et al., 2005), deliver the single scattering albedo (MODIS deep blue, Hsu et al., 2004), or provide derived quantities such as particle number concentrations (e.g. parameterization based on MERIS multi-spectral measurements, von Hoyningen-Huene et al., 2003; Kokhanovsky et al., 2006).

In this study the information content of measurements of the synergetic algorithm SYNAER for AATSR and SCIAMACHY is investigated. These instruments were conceived to improve our global knowledge and understanding of a variety of issues of importance for the chemistry and physics of the Earth atmosphere and potential changes resulting from either anthropogenic behaviour or natural phenomena. While not being the prime focus, aerosols are an important science target of these instruments. Both of the instruments are flown on the European platform ENVISAT which was launched on 1 March 2002. AATSR data have a resolution of $1 \mathrm{~km}$ at nadir, and are derived from measurements of reflected and emitted radiation taken at seven wavelengths: $0.55 \mu \mathrm{m}, 0.66 \mu \mathrm{m}, 0.87 \mu \mathrm{m}, 1.6 \mu \mathrm{m}, 3.7 \mu \mathrm{m}, 11 \mu \mathrm{m}$ and $12 \mu \mathrm{m}$. SCIAMACHY has a nadir and an additional limb viewing mode. Its nadir pixel size is $60 \times 30 \mathrm{~km}^{2}$ and it has a complete extended spectral range covering 240 to $1750 \mathrm{~nm}$ and 1940 to $2380 \mathrm{~nm}$ with a spectral resolution between 0.2 and $1.5 \mathrm{~nm}$. In the latest calibration version the crosscorrelation of spectrally and spatially integrated reflectances measured by both instruments and against another radiometer MERIS (Medium Resolution Imaging Spectrometer) onboard ENVISAT was found to satisfy high accuracy requirements with deviations on the order of $1 \%$ (Kokhanovsky et al., 2007).

At the German Remote Sensing Data Center (DFD) the aerosol retrieval method SYNAER was developed (HolzerPopp et al., 2002a) which delivers boundary layer aerosol optical depth and type over both land and ocean, the latter as percentage contribution of 9 representative components based on the OPAC (Optical Parameters of Aerosols and Clouds, Hess et al., 1998) dataset to AOD. The SYNAER method consists of two parts. In the first part the AATSR radiometer data are used to retrieve aerosol optical depth and surface reflectance with a dark field method exploiting single wavelength radiometer reflectances $(670 \mathrm{~nm}$ over land, $870 \mathrm{~nm}$ over ocean) for a selected aerosol type. In the second part the spectrometer data are then used to select the most plausible aerosol type by a least square fit of visible top-of atmosphere reflectance spectra at 10 wavelengths $(415,428$, $460,485,500,5516,523,554,615$, and $675 \mathrm{~nm}$ ).
As the estimation of the aerosol type is the most innovative part of SYNAER, a study provided an analysis of the information content of the second SYNAER part with regard to aerosol composition (Holzer-Popp et al., 2008). The purpose of the analysis in the work by Holzer-Popp et al, 2008 was to establish theoretically the information content of step 2 in the SYNAER retrieval, namely the choice of the most plausible aerosol mixture. The information content analysis in Holzer-Popp et al. (2008) estimated degrees of freedom for signal (DFS) for aerosol composition retrieval.

This paper is a logical continuation of the Holzer-Popp et al., 2008 work and concentrates mostly on the interpretation of the DFS values (their number being derived in the previous paper) in order to better understand the possibility to differentiate between aerosol types using a principal component analysis. We assume 2 DFS from the first step of the SYNAER algorithm (regarding AOD and surface reflectance) and up to 2-3 DFS for the second step (regarding aerosol type), as shown in Holzer-Popp et al. (2008). Consequently, the focus of this analysis was on exploiting the spectrometer measurements explicitly using the results of the first retrieval step, namely aerosol optical depth at $0.55 \mu \mathrm{m}$ and surface reflectance at $0.55,0.67$ and $0.87 \mu \mathrm{m}$ for each aerosol mixture. In the analysis of the information content 9 basic components (water soluble, water insoluble with high and low hematite content, sea salt accumulation and coarse mode, anthropogenic soot, biogenic soot and mineral dust with high and low hematite content) were used to define a set of 40 mixtures (see Table 1), which was then applied to radiative transfer calculations of simulated SCIAMACHY spectra. Table 1 shows the definition of the 40 mixtures used in the SYNAER retrieval method. The set of 40 mixtures is meant to model all principally existing aerosol types and allow for some variability in the composition of each type. Two groups of 20 mixtures, each are applied where either relative humidity or the absorption (hematite content) of the mineral components are altered. There is also a height variation for those mixtures with an elevated aerosol layer, for example in definition of mixtures 15-17 for desert dust outbreaks.

The set of 40 mixtures is meant to model all principally existing aerosol types and allow for some variability in the composition of each type. This set of mixtures has proven to provide a fit in the SCHIMACHY spectra retrieval which is in many cases at a $0.01 \%$ noise level. There is no desert dust mixed with biomass soot aerosol type in predefined types of the aerosol mixtures.

Cloud Screening in SYNAER is achieved through an adaption of the Advanced Very High Resolution Radiometer (AVHRR) Processing scheme Over cLouds, Land and Ocean (APOLLO), described in Saunders and Kriebel (1988), Kriebel et al. $(1989,2003)$ to AATSR at $1 \mathrm{~km}$ pixel resolution. This cloud screening scheme to AATSR has been adapted to overvome two shortcomings, which have to be accounted for in order to derive an accurate cloud mask for aerosol retrievals. First, heavy aerosol load over oceans 
Table 1. Pre-defined external aerosol mixtures of the basic components which are used in SYNAER. Adapted from Holzer-Popp et al. (2008). $\mathrm{WA}=$ watersoluble, $\mathrm{IN}=$ insoluble, $\mathrm{SS}=$ sea salt, $\mathrm{SO}=$ soot, $\mathrm{MI}=$ mineral dust.

\begin{tabular}{|c|c|c|c|c|c|c|c|}
\hline \multirow{2}{*}{\multicolumn{2}{|c|}{ No. }} & \multirow{3}{*}{$\begin{array}{l}\text { Name } \\
\text { Pure water-soluble }\end{array}$} & \multicolumn{5}{|c|}{$\begin{array}{l}\text { Component contributions to aerosol optical } \\
\text { depth (AOD) at } 0.55 \mu \mathrm{m}[\%]\end{array}$} \\
\hline & & & WA & IN & SS & SO & MI \\
\hline 1 & 21 & & 100 & & & & \\
\hline 2 & 22 & Continental & 95 & 5 & & & \\
\hline 3 & 23 & & 90 & 10 & & & \\
\hline 4 & 24 & & 85 & 15 & & & \\
\hline 5 & 25 & Maritime & 30 & & 70 & & \\
\hline 6 & 26 & & 30 & & 70 & & \\
\hline 7 & 27 & & 15 & & 85 & & \\
\hline 8 & 28 & & 15 & & 85 & & \\
\hline 9 & 29 & Polluted watersoluble & 90 & & & 10 & \\
\hline 10 & 30 & & 80 & & & 20 & \\
\hline 11 & 31 & Polluted Continental & 80 & 10 & & 10 & \\
\hline 12 & 32 & & 70 & 10 & & 20 & \\
\hline 13 & 33 & Polluted Maritime & 40 & & 50 & 10 & \\
\hline 14 & 34 & & 30 & & 50 & 20 & \\
\hline 15 & 35 & Desert Outbreak & 25 & & & & 75 \\
\hline 16 & 36 & & 25 & & & & 75 \\
\hline 17 & 37 & & 25 & & & & 75 \\
\hline 18 & 38 & Biomass Burning & 85 & & & 15 & \\
\hline 19 & 39 & & 70 & & & 3 & \\
\hline 20 & 40 & & 55 & & & 45 & \\
\hline
\end{tabular}

(mainly mineral dust, to minor parts smoke plumes from wildfires) is classified as "cloudy" by APOLLO and these AATSR pixels are then not used for the retrieval of AOD in SYNAER, leading to somewhat too small AOD values in the dust belts. The second shortcoming is an improper detection of shallow cumulus cloud cover over land due to a simple temperature threshold test for the rejection of cloudy pixels in order to not classify desert surfaces as low clouds (for details see Holzer-Popp et al., 2002a). In the present theoretical study in order to eliminate cloudiness problem we are concentrating only on clear sky pixels and assume no error due to cloud correction.

In order to retrieve AOD with an accuracy of 0.1 the surface albedo of the treated dark field should be known with an accuracy of 0.01 (see e.g. Holzer-Popp et al., 2002a). To achieve this accuracy in an automatic retrieval procedure over land for AATSR, dark fields are selected from a combination of thresholds for the normalized vegetation index NDVI and the reflectance R1.6 in the mid-infrared at $1670 \mathrm{~nm}$ (over ocean a different scheme is used, which is described in Holzer-Popp et al., 2002a). For these dark fields $\mathrm{R} 0.670$ is estimated using a correlation with R1.6.

The focus of information content analysis is on the second retrieval step exploiting the spectrometer measurements. This uses the results of the first retrieval step, namely aerosol optical depth at $550 \mathrm{~nm}$ and surface reflectance at 550,670 and $870 \mathrm{~nm}$ for each aerosol mixture.
So the spectral surface reflectance is considered to be known from the first retrieval step in SYNAER and not included as the part of the state vector in DFS analysis using Rodgers (2000) optimal estimation.

The number of Degrees of Freedom of the Signal (DFS) and the separable aerosol components are quantified by applying an information content analysis (Sect. 2) to synthetic reflectance spectra for a large number of scenarios with various aerosol models, observation geometries and surface types. The information content theory (Rodgers, 2000) was applied in an unusual way, namely to independently assess the information content of the existing retrieval method and discern the input of different aerosol types in the measurements. This new point of view on the retrieval problem allows the derivation of some facts about capabilities and limitations of SYNAER to estimate aerosol composition. The results of the information content analysis are immediately applicable to the SYNAER algorithm, since the DFS analysis is applied to the synthetic reflectance data stored in the Look-Up Tables (LUT) of SYNAER. The results of the DFS analysis depend on the aerosol parameter ranges covered by the set of aerosol models considered. The basic assumption made in this study is that the aerosol models cover the natural variability of tropospheric aerosol. The number of DFS obtained is representative for the number of aerosol parameters that can be retrieved independently from reflectance measurements provided that the surface albedo spectrum is 
accurately known and the presence of clouds can be completely excluded or corrected, see Holzer-Popp et al. (2002).

This introduction is followed by the description of used method for information content analysis. An analysis of the information content of the (additional) second retrieval step of SYNAER with regard to aerosol composition including realistic noise in the retrieval is made (Sect. 2). The number of Degrees of Freedom of the Signal (DFS) is quantified by applying Singular Value Decomposition Analysis to synthetic reflectance spectra (Sect. 3.1) for a large number of scenarios with various aerosol models, observation geometries and surface types. Section 3.2 gives an overview of the derived results for DFS and its interpretation. Section 3.3 deals with the distinction between aerosol types in the retrieval. The weights associated with the DFS provide a graphical view on the aerosol retrieval. This concept is used to investigate the cross correlations of the retrieved aerosol types. The paper concludes with a discussion and conclusions in Sect. 4.

\section{Analysis of information content}

The method used to examine and analyse the information content is the singular value decomposition (SVD). The following theoretical description is based on the inverse methods methodology (Rodgers, 2000). SVD is a useful tool to identify the dominant parts of the observations. This allows identifying the number of parameters which can be retrieved from observations and analysing the separability of the variables retrieved. Generally, the number of observations does not equal the degrees of freedom because not all observations are uncorrelated.

For any remote measurement, we can define relationship between real state of the atmosphere and measurement:

$y=F(x, b)+\varepsilon$

where $\boldsymbol{y} \in \boldsymbol{R}^{m}$ is the measurements vector of dimension $m$, i.e. reflectances at $m$ wavelengths; $\boldsymbol{x} \in \boldsymbol{R}^{n}$ is the state vector of dimension $n ; \boldsymbol{b}$ is the vector containing all the other parameters necessary to define the radiative transfer through the atmosphere to the spacecraft, $\boldsymbol{F}: \boldsymbol{R}^{n} \rightarrow \boldsymbol{R}^{m}$ is the forward model that describes the physics of the measurements that map from the state space to the measurements space and $\boldsymbol{\varepsilon}$ $\in \boldsymbol{R}^{m}$ is the measurement error vector.

In this work some aspects of principal component analysis were used. Principal component analysis is a powerful tool that helps to clarify the number of parameters that can be retrieved from a given set of observations. This approach is particularly useful for the analysis of the large measurement sets where a direct physical analysis is difficult due to high number of measured and retrieved parameters. In this study there is an attempt to infer information about the correlation or independence of retrieved types of aerosol parameters. A similar analysis for different aerosol parameters was accomplished in (Veihelmann et al., 2007), where the principal component analysis was applied, which works as follows: the set of $\boldsymbol{n}$ simulated reflectance measurements is stored in the measurement matrix $\mathbf{Y}$ with elements $y_{\mathrm{nm}}$, where the column vectors are the $\boldsymbol{n}$ reflectance vectors from the state space $\boldsymbol{R}^{n}$ and the index $m$ indicates the wavelength band. The measurement matrix $\mathbf{Y}$ is normalized such that for each wavelength, the mean value of all measurements is zero and the standard deviation is unity. The covariance matrix $\mathbf{A}=\mathbf{Y} \mathbf{Y}^{T}$ is diagonalized according to $\mathbf{A}=\mathbf{V}^{T} \mathbf{D V}$ such that the row vectors of the matrix $\mathbf{V}$ form an orthonormal set of eigenvectors. Each reflectance measurement can be decomposed into a weighted sum of some basic components:

$y_{\mathrm{m}}=\hat{y}_{\mathrm{m}}+\delta=\sum_{\mathrm{k}}^{k_{\max }} w_{\mathrm{mk}} v_{\mathrm{k}}+\delta$

Where $\hat{y}_{\mathrm{m}}$ are the elements of the reconstructed measurement matrix with an error $\delta$, with weights $w_{\mathrm{mk}}$ being the elements of the matrix $\mathbf{W}$. Naturally, when a measurement is reconstructed using all $K$ basic components $\left(k_{\max }=K\right.$, in Eq. 2$)$, the error $\delta$ is zero. The sum in Eq. (2) can be truncated at $k_{\max }<K$ without any loss of information as long as the error $\delta$ is smaller than the error due to instrument noise.

The matrix $\mathbf{V}$ transforms the measurement matrix $\mathbf{Y}$ into the space of so called weights. D consists of eigenvalues of matrix $\mathbf{A}$. These eigenvalues of the transformed $\mathbf{Y}$ can be interpreted as a measure for the importance (DFS) for each aerosol component. In this study, a very similar analysis method is performed. For the implementation of the technique of identifying different aerosol types see Sect. 3.3.

The measurement vector for this theoretical analysis of the SYNAER retrieval consists of simulated spectra at 10 $(m=10)$ wavelengths for $40(n=40)$ different aerosol mixtures with a given surface type. As a state vector $\boldsymbol{x}$ for the analysis we consider only 40 different aerosol models composed by 9 basic components. So the a priori covariance matrix $\mathrm{Sa}$ is the associated covariance matrix for these a priori values and knowledge about the $\boldsymbol{x}$ vector, i.e. 40 aerosol models. The method rests on the assumption, that a linear approximation of $\boldsymbol{F}$ is sufficiently exact at some reference state $x_{0}$ :

$y-F\left(x_{0}\right)=\frac{\partial F}{\partial x}\left(x-x_{0}\right)+\varepsilon=K \cdot\left(x-x_{0}\right)+\varepsilon$

where $\mathbf{K}$ is the weighting function matrix of dimension $m \times n$. Each element of $\mathbf{K}$ is the partial derivative of a forward model element with respect to a state vector element:

$k_{i j}=\frac{\partial F(x)_{i}}{\partial x_{j}} ; \forall i=1 . . m, \forall j=1 . . n$

$\boldsymbol{F}$ maps the state space into the measurement space according to the Forward Model. It is necessary to have some prior information about the state, to constrain the solution. 
The information content can be condensed into the Degrees of Freedom for Signal (DFS). DFS can be interpreted as the number of independent linear combinations of the state vector that can be independently retrieved from the measurements. It is given by:

$\mathrm{DFS}=\sum \frac{\lambda_{i}^{2}}{1+\lambda_{i}^{2}}$

where $\lambda_{i}$ are the singular values of $\left(\mathbf{S}_{\varepsilon}\right)^{-1 / 2} \mathbf{K}\left(\mathbf{S}_{\mathrm{a}}\right)^{1 / 2}$.

$\boldsymbol{S}_{\varepsilon}$ and $\boldsymbol{S}_{\mathrm{a}}$ correspond to measurement covariance matrix and a priori covariance matrix. The measurement covariance matrix $\mathbf{S}_{\varepsilon}$ has a diagonal form, with diagonal elements equal to the relative error of measured reflectance spectrum values. The structure of the a priori covariance matrix $\mathbf{S}_{\mathrm{a}}$ is shown on Fig. 1. The elements of this matrix are derived from Table 1 using an ordinary definition of covariance:

$S_{\mathrm{a}}^{i j}=\frac{1}{n} \sum\left(r_{i}-\breve{r}\right)\left(s_{j}-\breve{s}\right)$

where $r_{i}, s_{j}$ are the percentage contributions of the 9 basic components for each aerosol mixture from Table $1 ;, \breve{s}$ are the mean values of $r_{i}, s_{j}, i=1 . . n, j=1 . . n ; n$ is the total number of mixtures.

\section{Results}

In this section the results of the DFS analysis are shown and discussed for a large number of scenarios. The capabilities of the multi-wavelength algorithm are assessed using the number of DFS as well as the weights of the measurement matrix.

\subsection{Synthetic reflectance data}

For a fast application in aerosol retrieval precalculated radiative transfer tables are used. For this study radiative transfer simulations are based on the Look-Up Tables (LUT) which includes simulations for many different aerosol cases for various aerosol types, including biomass burning, desert dust, weakly absorbing and water soluble aerosols. The aerosol mixtures cover a range of optical parameters, as well as a range of atmospheric scenarios with varying AOD. Altogether, more than 2500 simulated reflectances with different geometry and aerosol parameters are taken into account.

\subsection{Overview for number of degrees of freedom for signal}

The singular values used in definition of DFS drop fast with increasing order: for most geometries and surface types, more than $70 \%$ of the reflectance measurements can be reproduced within the measurement error when including 2 to 5 singular values; singular values of higher orders are then not relevant for most reflectance measurements since their contribution to the reflectance is dominated by instrument noise (Holzer-Popp et al., 2008).

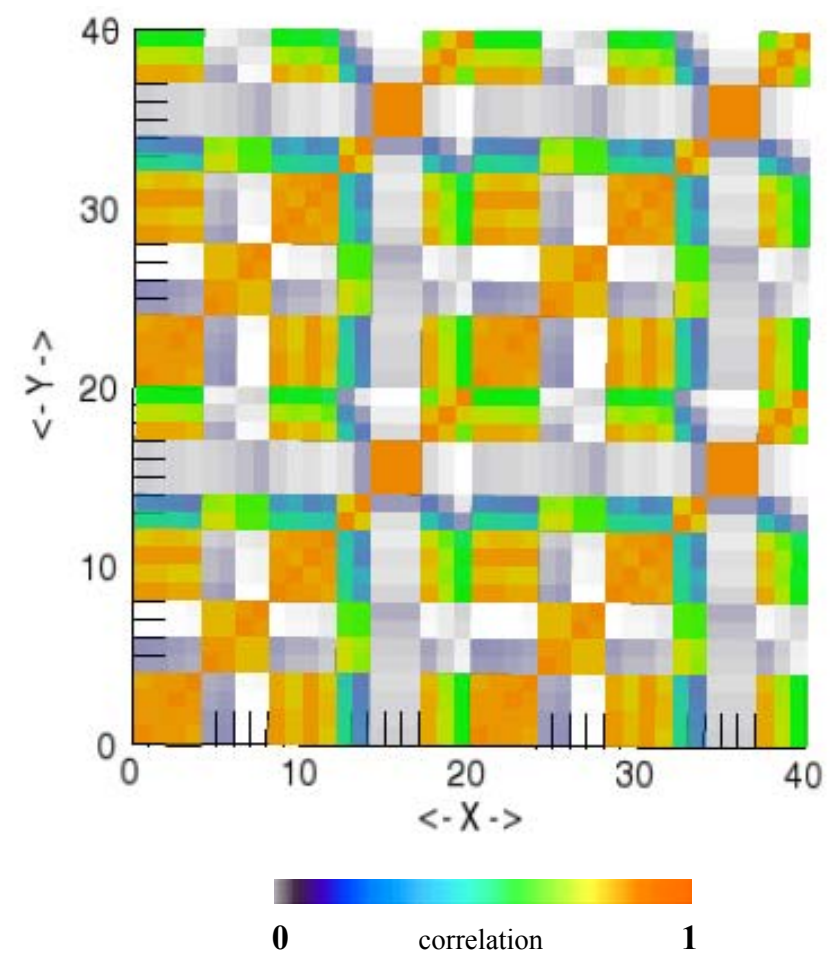

Fig. 1. Graphical representation of the correlation between 40 predefined aerosol mixtures. The maximum correlation elements are on the main diagonal of the matrix (self correlation). There is also strong correlation between first and second halves of the 40 aerosol mixtures because of similarity between these two subsets. Standard matrix normalization procedure (dividing by maximum element) was used.

Building on earlier work, the number of DFS calculated as explained at the end of Sect. 2 depends on the observation geometry, the surface albedo and the choice of the noise threshold. In order to give an overview of the information content of reflectance measurements, histograms of the number of DFS for various scenarios are shown. In Fig. 2 histograms of the number of DFS are plotted for the observation geometry for varying solar elevation angles (SEA), applying surface albedo spectrum for soil. The measurement error in this case is equal 10e-6. Histograms for the number of DFS of all aerosol models are shown for a series of geometries with sun elevation angles ranging from $12.5^{\circ}$ to $90^{\circ}$. The information content of measurements is a monotone function of satellite angle. In most cases the number of DFS varies between 2 and 5 .

Optical depth dependence of the number of DFS is depicted in Fig. 3 for the observation geometry with AOD, ranging from 0 to 0.7 , SEA equal to $42.5^{\circ}$ and surface type soil. From the point of view for DFS, soil case signals are weaker in comparison with vegetation case, as the DFS values for soil in average are smaller than for vegetation case. However, the principal findings of the former result 


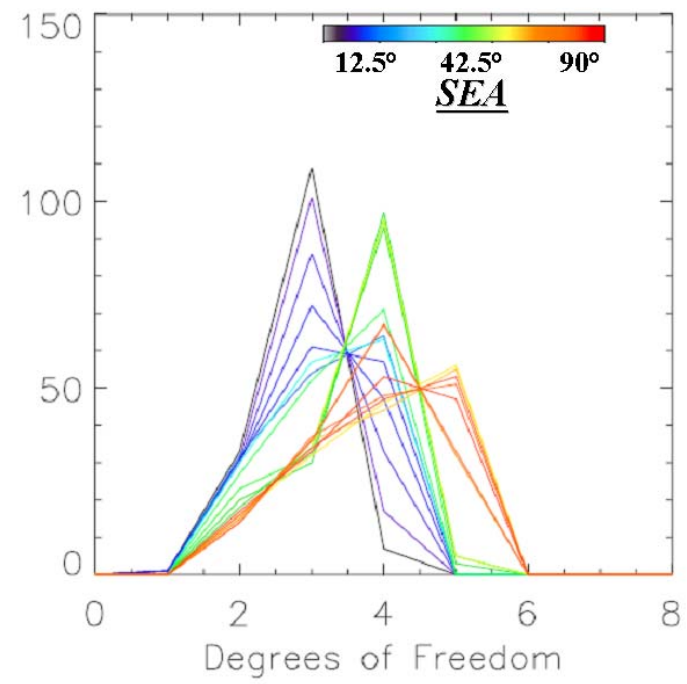

Fig. 2. Histogram for various scenarios (y-axis) of the number of DFS of reflectance measurements for retrieval with different sun elevation angle (SEA) for a case with surface albedo spectra over soil.

also applicable in this case. There is an accumulation point $(\mathrm{DFS}=4)$ about $\mathrm{AOD}=0.16$, from which the distribution of histograms is quite similar to each other. This means that further increase of AOD does not contribute to any additional aerosol information in the retrieval. In this case the variance of the measurement error covariance matrix is of order 10e- 6 .

In Fig. 4 the histogram of the number of DFS is plotted for the observation geometry with solar elevation angle $42.5^{\circ}$, surface albedo spectrum for vegetation and varying measurement observation error.

As a starting value of measurement error covariance (i.e. the square of the error) in this analysis we took 10e-6, which corresponds to $1 \%$ of reflectance spectra from SCIAMACHY reflectances in the visible (typically at 0.1 ), assuming explicit knowledge of surface type and AOD from the first AATSR step. So we don't consider albedo uncertainty as the part of measurement error at this step. After that, in order to assess the sensitivity, we varied the measurement error in large steps (10e-6, 6e-7, 3e-8) and in small steps (4e-7, 5e-7, 6e-7). The choice of such values for the observation error variance is based on the attempt to explore the dependency of DFS from observation error. For the typical observation error variance of order 10e- 6 obtained DFS varies between 3 and 4 . When an error of $\sigma_{\varepsilon}^{2}=6 \mathrm{e}-7$ is assumed, there are 4 degrees of freedom for most of the aerosol measurements (yellow line). If this noise value is relaxed by assuming a lower error in observations (with the observation error values of $\sigma_{\varepsilon}^{2}=5 \mathrm{e}-7$ (green line), $\sigma_{\varepsilon}^{2}=4 \mathrm{e}-7$ (blue line), $\sigma_{\varepsilon}^{2}=3 \mathrm{e}-8$ (purple line)), a further increase of degrees of freedom is monitored. The choice of such values for observation error variance is based on the attempt to explore the dependency of DFS from observation er-

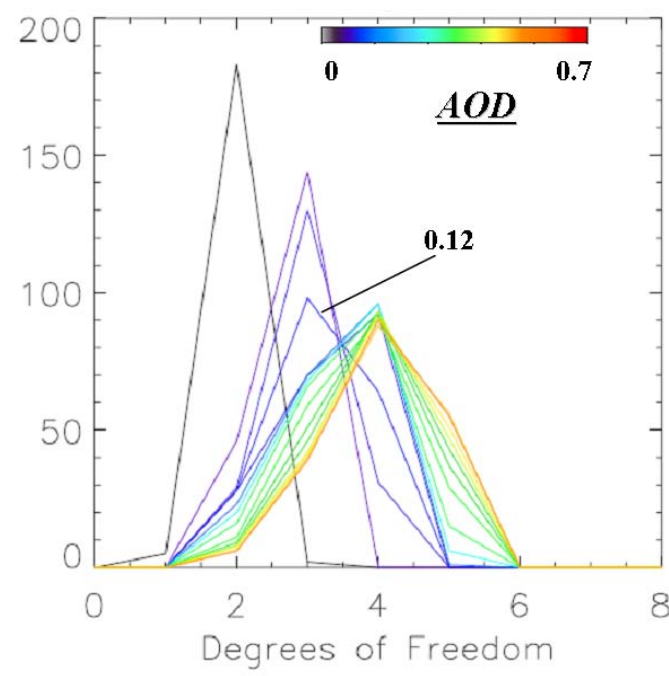

Fig. 3. Histogram for various scenarios (y-axis) of the number of DFS of reflectance measurements for aerosol models as a function of Aerosol Optical Depth (AOD) for a case with surface albedo spectra for soil.

ror in large-step series of the error (10e-6, 6e-7, 3e-8) and in small-step series of the observation error (4e-7, 5e-7, 6e-7).

\subsection{Distinction between aerosol types}

In SYNAER a look-up table approach is used. Radiative transfer calculations are pre-calculated for many values of the parameters, after that results are compared with measurements until the best "fit" is obtained. There is a problem in such a method, which is the lack of uniqueness in the solutions, but this is the problem of all ill-posed inversions. We used a classical tool from statistical methods (PCA) to explore this problem, extract the uncorrelated and independent variables and concentrate attention only on main (principal) aerosol type components which should be retrieved. Such an approach has advantages (in comparison with, for example, Factor-analysis) and is useful since it will give us in an unbiased way the number of parameters (and their interpretation) that can be retrieved.

The PCA analysis is aiming only at the distinction of aerosol types. The spectral surface reflectance is considered to be known from the first retrieval step in SYNAER and not included as the part of the state vector in the DFS analysis.

The capability of the SYNAER algorithm to discern aerosol types is investigated using the distribution of the different aerosol retrieval scenarios in the space of weights. The first two weights from Eq. (2): $w_{\mathrm{m} 1}$ and $w_{\mathrm{m} 2}$ indicate, whether aerosol models can be discerned or not, for cases where at least two DFS are available. If three DFS are available, the first three weights have to be taken into account in order to decide, whether aerosol models can be discerned or not. Figure 5a shows the variation of the AOD in the space of 


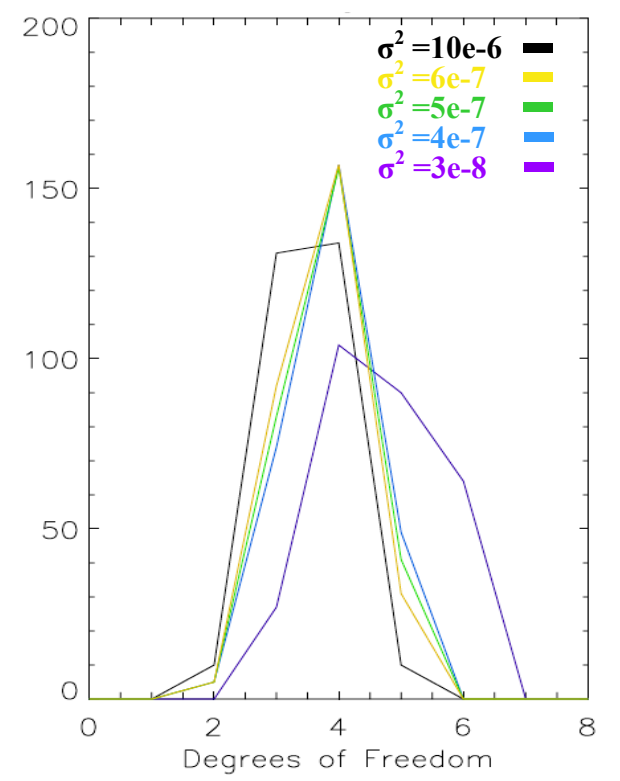

Fig. 4. Histogram for various scenarios (y-axis) of the number of DFS of SYNAER reflectance measurements using different observation errors for spectrum measurements. The black histogram corresponds to observational measurement variance $\sigma^{2}=10 \mathrm{e}-6$, yellow corresponds to $\sigma^{2}=6 \mathrm{e}-7$, green line: $\sigma^{2}=5 \mathrm{e}-7$, blue line: $\sigma^{2}=4 \mathrm{e}-7$, violet line: $\sigma^{2}=3 \mathrm{e}-8$. Large-step series of the error: $10 \mathrm{e}-6,6 \mathrm{e}-7,3 \mathrm{e}-8$ and small-step series of the observation error: $4 \mathrm{e}-$ 7, 5e-7, 6e-7 correspondingly.

the first two weights for all 40 aerosol mixtures from Table 1. Solid lines connect models with identical aerosol type but variable aerosol optical depth ranging from 0 to 0.7 , while all other parameters, such as observation angle, albedo, aerosol type are constant. When the solid lines in this plot construct a larger angle between each other, using DFS interpretation from Sect. 2, Eq. (5) it can be interpreted as uncorrelated measurements of aerosol mixtures with larger DFS number. The separability is also defined by a minimum distance to noise measurements, e.g. from the figure $\mathrm{AOD}>0.15$. The independent retrieval becomes more pronounced when the AOD increases. It appears that the major groups of the aerosol mixtures can be separated rather well in most cases with $A O D>0.15$. Mineral dust aerosol with high and low hematite content are also represented with two separate bundles. The measurements from Fig. 5a containing independent information about desert dust and continental aerosol form the fact that these aerosol types are near-orthogonal in the space of weights. But this does not require that either desert dust or continental aerosol generate the basis in this space. In the same manner such retrieval parameters as surface type and AOD also can not be explicitly assigned to some DFS value.

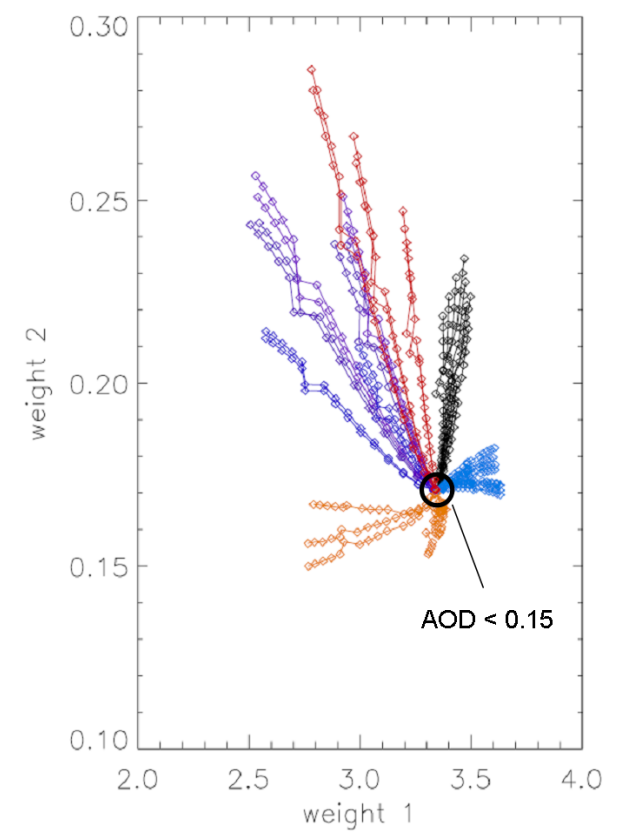

Fig. 5a. Weights for the first and second eigenvalue component for 40 aerosol mixtures for all measurement scenarios. Retrieval scenarios with the same parameters but with varying optical depth are connected with solid lines. The domain of diesel and biomass burning (red) overlaps with the domains of polluted aerosol (dark blue and violet). Other domains: maritime (light blue), continental (black) and desert dust (sienna) are distinguishable from one another.

However the domain of biomass burning aerosols (red) overlaps with the domain of polluted aerosols (violet). This overlap is less pronounced in the space of second and third weights (Fig. 5b), where the same 40 predefined aerosol mixtures are represented. So for DFS $\geq 3$ here also separation becomes possible.

A similar analysis was made separately for each predefined SYNAER surface type. The distinction of domains for different aerosol types is based not only on the angle between AOD solid lines, but also depends on curvature of AOD lines, for example in Fig. 6a, in the case of soil surface type, some of the violet lines (polluted maritime aerosol) at the beginning have the same tendency as the other types of aerosol lines, but for larger values of AOD violet lines have a completely different curvature. The analysis over this suface albedo corresponds to cases with not very large values of DFS, as compared with the maximum DFS case conditions seen in vegetation surface type. Distinguishing between aerosol types in this case is difficult. For comparison, the distribution of aerosol models in the space of first two weights for the sand surface type is given (Fig. 6b). In this case it is quite difficult to say anything about distinguishing of aerosol types - all domains are mixed in a nontrivial way. This result corresponds well to the retrieval limitations of SYNAER over bright surfaces such as sand or snow (Holzer-Popp et 


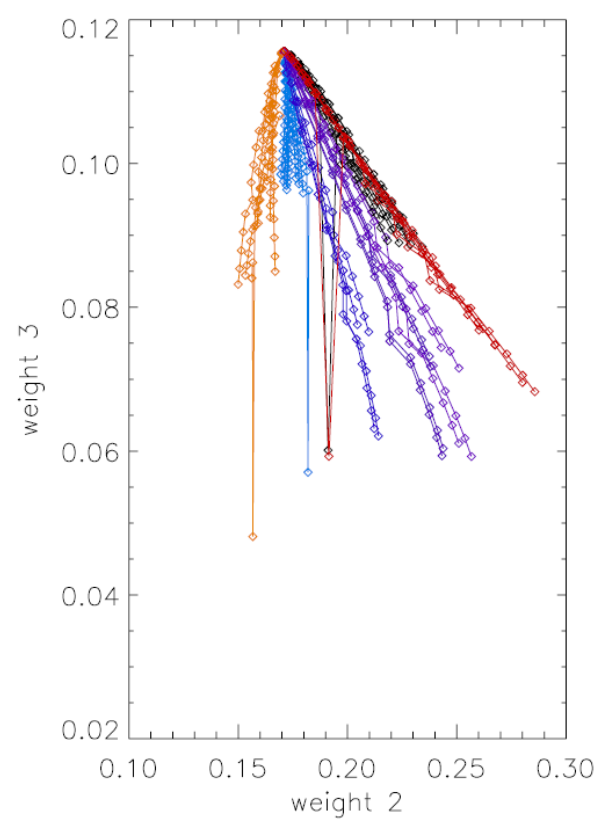

Fig. 5b. Distribution of retrieval in the space of second and third weights for 40 aerosol mixtures for all measurement scenarios. Retrieval scenarios with the same parameters but with varying optical thickness are connected with solid lines. There are five domains marked with different colours: the domain of diesel and biomass burning (red), the domain of polluted aerosol (dark blue and violet). Other domains: maritime (blue), continental (black) and desert dust (sienna). In this case black and red lines are not separated.

al., 2008). On the other hand one of the most favourable results is shown on Fig. 6c, where the analysis for meadow surface type is made. Domains of different aerosol models are well distinguished. The small overlap over the lower part of the domain is due to incomplete distinction between biomass burning and polluted water soluble aerosol and similar as it was indicated on Fig. 5a where a small overlap can be also observed. The retrieval still has problems with aerosol type identification in the lower part of the domain, despite favourable surface type: meadow. This feature confirms once more the necessity for the reduction of the 40 predefined aerosol mixtures to a smaller number of aerosol type definitions.

Such plots have been investigated for various typical observation geometries and various surface type spectra. The differences between absolute values and starting point value for the solid lines on these figures (Fig. 6a, b and c) are caused by the differences between AOD measurement values which form the structure of analysing matrices for each surface type case.

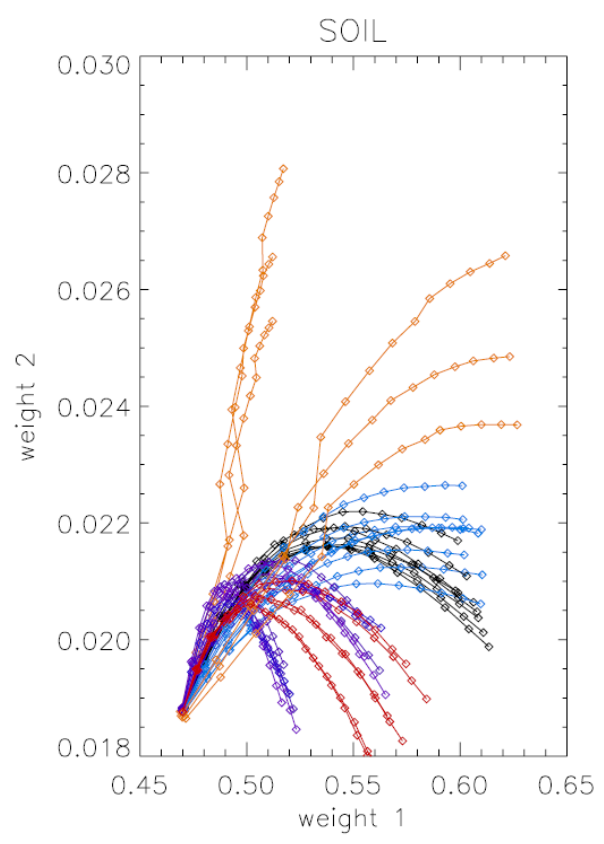

Fig. 6a. Distribution of retrieval in the space of first and second weights for 40 aerosol mixtures only for the surface type soil.

\section{Discussion and conclusions}

The motivation of the present investigation is to explore aerosol type information content with the help of principal component analysis. This theoretical analysis is performed for a large number of scenarios with various geometries and surface albedo spectra for water, soil, vegetation etc. When the surface albedo spectra and AOD is accurately known and clouds are absent or are corrected, SCIAMACHY reflectance measurements have 2 to $3^{\circ}$ of freedom that can be attributed to aerosol type parameters. This was the main result from Holzer-Popp at al. (2008) work. The present work goes further in investigation of the correspondence of derived DFS to distinction of aerosol type. The capability of the SYNAER algorithm to discern aerosol types is investigated using the distribution of the models in the space of weights of the principal components. This is a new step in comparison with the previous Holzer-Popp at al. (2008) paper.

The main assumptions on aerosol retrieval which have been made are as follows:

- Particles are assumed to be spherical.

- There are 40 aerosol mixtures which are assumed to cover natural variability of aerosol in the troposphere.

- The error measurement of the spectrometer is considered to vary between $1-0,3 \%$ of measured reflectances.

- The PCA for the SYNAER algorithm relies on a-priori data for surface albedo spectra and AOD, which are derived from the previous retrieval step. The AOD and 


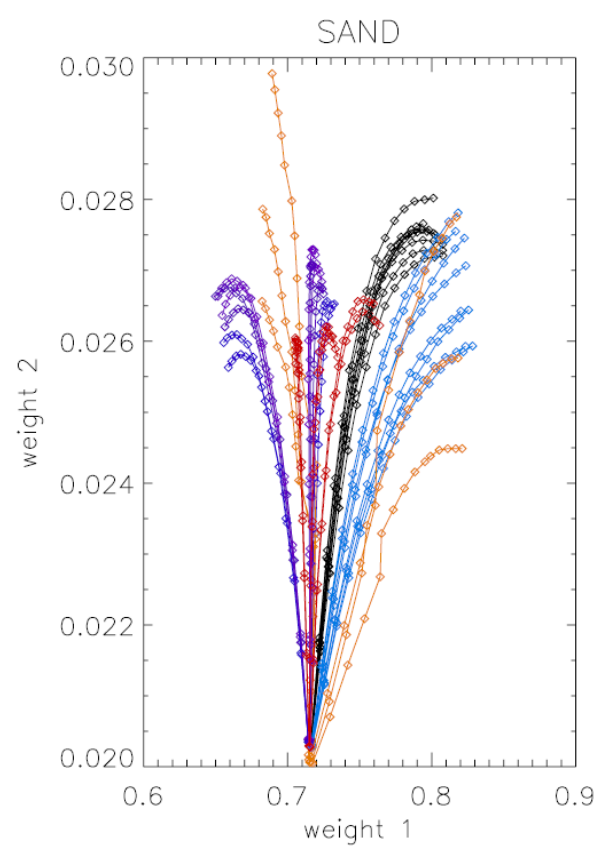

Fig. 6b. Distribution of aerosol models in the space of first and second weights for 40 aerosol mixtures for the surface type sand.

albedo uncertainties are excluded from the present error analysis.

A good overview of the discretization of radiative transfer is represented in Hasekamp et al. study. This work presents an analytical linearization of vector radiative transfer with respect to physical properties of spherical aerosols. It is quite close to the analysis of information content discussed in ACP paper by Holzer-Popp et al. (2008). There, we also use linearization of radiative transfer around some point of state space with respect to different aerosol type properties. The present paper concentrates on PCA analysis applied for aerosol type in order to understand the separation of the aerosol types.

The information content of SYNAER simulated reflectance measurements has been investigated using DFS analysis. This analysis has been performed with a total of about 2500 synthetic SCIAMACHY reflectance measurements in wavelength bands between $400 \mathrm{~nm}$ to $700 \mathrm{~nm}$. The number of DFS for reflectance measurements varies between 2 and 6, depending on AOD, surface type, observation angle and noise. The number of DFS reported here are consistent with the results of a preliminary short theoretical study on the information content (Holzer-Popp et al., 2008). Derived DFS from that study can now be assigned in appropriate way to the different types of aerosol. The weights of all aerosol models have been employed to investigate the capability of the SYNAER algorithm to distinguish different aerosol types. Consider the angle between solid lines in Fig. 5 as an index of discernment for aerosol models. Desert dust, continen-

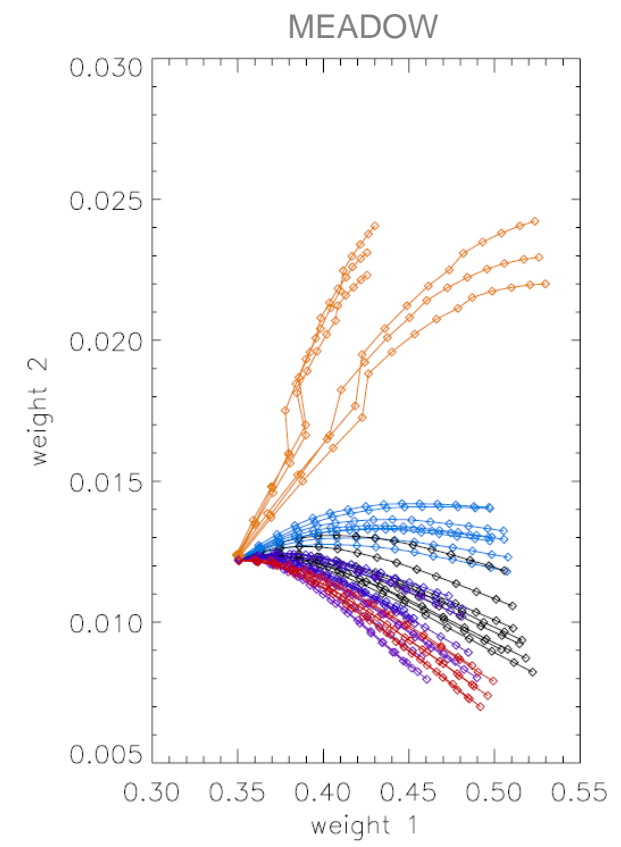

Fig. 6c. Distribution of aerosol models in the space of first and second weights for 40 aerosol mixtures for the surface type meadow.

tal, sea salt and polluted aerosol can be discerned well from each other. Desert dust can be discerned from other types of aerosol with the best index. Some aerosol cases for biomass burning cannot be distinguished from polluted aerosol in the space of the first two weights. This ambiguity depends on the number of DFS and is less pronounced if three or more degrees of freedom of the signal can be assigned to aerosol. However, in the most typical SYNAER measurement cases, with sufficient solar angle and appropriate surface type, more than two DFS are available and then a third weight can be used in order to distinguish aerosol types.

Results indicate that major groups of physical aerosol types can be well separated from other retrieval parameters. The problem is solved when three or more DFS are available. The results of the information content analysis can be used in order to determine the number of DFS for a given single spectrum. This quantity can be provided as additional diagnostic output of the aerosol retrieval using the SYNAER algorithm. The results of this study will build the basis to determine a best suited reduced set of aerosol mixtures for the SYNAER retrieval. In an ideal retrieval case we are trying to have a uniform distribution of aerosol types in the PCA weighting domain. Figure 7 suggests theoretically such an optimal distribution of 7 aerosol types circular around the $\mathrm{AOD}=0$ point in the meadow surface case. With this selection the reduced number of aerosol mixtures will be clearly differentiated and will cover a wide range of small (upper part) and large (lower part) as well as non-absorbing (right side) and absorbing (left side) aerosol types. 


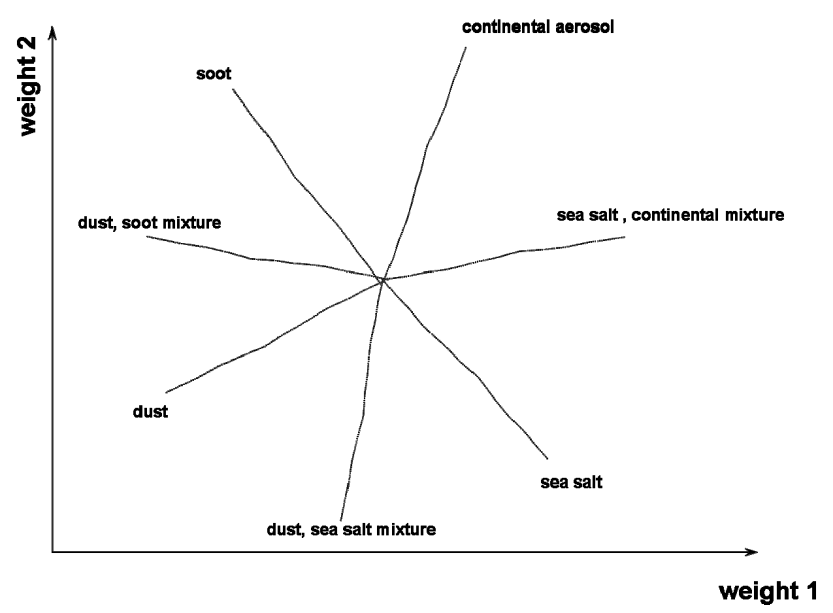

Fig. 7. Distribution of aerosol models in the space of first and second weights in perfect case of the retrieval.

The main results of this work will be further used in assimilation procedure of satellite data from SYNAER in chemical transport model. The main focus will be concentrated on tuning of error covariance matrices in assimilation using DFS retrieval information.

Acknowledgements. This work was supported by German Aerospace Center. Thanks are especially given to Thomas HolzerPopp.

Edited by: P. K. Bhartia

\section{References}

Chowdhary, J., Cairns, B., Mishchenko, M., and Travis, L.: Retrieval of aerosol properties over the ocean using multispectral and multiangle photopolarimetric measurements from the research scanning polarimeter, Geophys. Res. Lett., 28(2), 243246, 2001.

Deuzé, L., Bréon, F. M., and Devaux, C.: Remote sensing of aerosols over land surfaces from POLDER-ADEOS-1 polarized measurements, J. Geophys. Res., 106(D5), 4913-4926, 2001.

Hasekamp, O. P. and Landgraf, J.: Linearization of vector radiative transfer with respect to aerosol properties and its use in satellite remote sensing, J. Geophys. Res., 110(D4), D04203, doi:10.1029/2004JD005260, 2005.

Hess, M., Köpke, P., and Schult, I.: Optical Properties of Aerosols and Clouds: The Software package OPAC, B. Am. Meteorol. Soc., 79, 831-844, 1998

Holzer-Popp, T., Schroedter, M., and Gesell, G.: Retrieving aerosol optical depth and type in the boundary layer over land and ocean from simultaneous GOME spectrometer and ATSR-2 radiometer measurements, 1, Method description, J. Geophys. Res., 107(D21), AAC16-1-AAC16-17, 2002a.
Holzer-Popp, T., Schroedter-Homscheidt, M., Breitkreuz, H., Martynenko, D., and Klser, L.: Improvements of synergetic aerosol retrieval for ENVISAT, Atmos. Chem. Phys., 8, 7651-7672, doi:10.5194/acp-8-7651-2008, 2008.

Hsu, N. C., Tsax, S.-C., and King, M.: Aerosol Properties Over Bright-Reflecting Source Regions, IEEE T. Geosci. Remote, 42(3), 557-569, 2004.

Kaufman, Y. J., Tanre, D., Gordon, H. R., Nakajima, T., Lenoble, J., Frouin, R., Grassl, H., Herman, B. M., King, M. D., and Teillet, P. M.: Passive remote sensing of tropospheric aerosol and atmospheric correction for the aerosol effect, J. Geophys. Res., 102, 16815-16830, 1997a.

Kaufman, Y. J., Tanre, D., Remer, L. A., Vermote, E. F., Chu, A., and Holben, B. N.: Operational remote sensing of tropospheric aerosol over land from EOS moderate resolution imaging spectrometer, J. Geophys. Res., 102, 17051-17067, 1997b.

Kaufman, Y. J., Tanre, D., and Boucher, O.: A satellite view of aerosols in the climate system, Nature, 419, 215-223, 2002.

Kokhanovsky, A. A., Bramstedt, K., von Hoyningen-Huene, W., and Burrows, J. P.: The intercomparison of top-of-atmosphere reflectivity measured by MERIS and SCIAMACHY in the spectral range of 443-865 nm, IEEE T. Geosci. Remote, 4, 293-296, 2007.

Kokhanovsky, A. A., von Hoyningen-Huene, W., and Burrows, J. P.: Atmospheric aerosol load as derived from space, Atmos. Res., 81, 176-185, 2006.

Kriebel, K. T., Saunders, R. W., and Gesell, G.: Optical properties of clouds derived from fully cloudy AVHRR pixels, Beitraege zur Physik der Atmosphaere, 8, 723-729, 1989.

Kriebel, K. T., Gesell, G., Kästner, M., and Mannstein, H.: The cloud analysis tool APOLLO: Improvements and Validation, Int. J. Remote. Sens., 24, 2389-2408, 2003.

Rodgers, C. D.: Inverse methods for atmospheric sounding, Theory and Practice, University of Oxford, UK, 2000.

Tanré, D., Herman, M., and Kaufman, Y. J.: Information on aerosol size distribution contained in solar reflected spectral radiances, J. Geophys. Res., 101(D14), 19043-19060, doi:10.1029/96JD00333, 1996.

Veefkind J. P., de Leeuw, G., Durkee, P. A., Russell, P. B., Hobbs, P. V., and Livingston, J. M.: Aerosol optical depth retrieval using ATSR-2 data and AVHRR data during TARFOX, J. Geophys. Res., 104(D2), 2253-2260, 1999.

Veihelmann, B., Levelt, P. F., Stammes, P., and Veefkind, J. P.: Simulation study of the aerosol information content in OMI spectral reflectance measurements, Atmos. Chem. Phys., 7, 3115-3127, doi:10.5194/acp-7-3115-2007, 2007.

von Hoyningen-Huene, W., Freitag, M., and Burrows, J. B.: Retrieval of aerosol optical thickness over land surfaces from top-of-atmosphere radiance, J. Geophys. Res., 108, D94260, doi:10.1029/2001JD002018, 2003. 